EXTENDED REPORT

\title{
Silica exposure is associated with increased risk of developing rheumatoid arthritis: results from the Swedish EIRA study
}

\author{
P Stolt, H Källberg, I Lundberg, B Sjögren, L Klareskog, L Alfredsson, the EIRA study \\ group*
}

Ann Rheum Dis 2005;64:582-586. doi: 10.1136/ard.2004.022053

See end of article for authors' affiliations

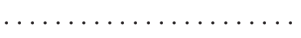

Correspondence to: Dr Patrik Stolt, Institute of Environmental Medicine, Karolinska Institutet, Box 210, S-171 77 Stockholm, Sweden; patrikstol+@ swipnet.se

Accepted 12 August 2004 Published Online First 19 August 2004
Objective: To study the association between silica exposure and rheumatoid arthritis and how it is modified by cigarette smoking.

Methods: Data were analysed from 276 male cases and 276 male controls aged 18 to 70 years, included in a Swedish population based study between May 1996 and June 2001. A case was defined as a person recently diagnosed with rheumatoid arthritis according to the ACR criteria. Controls were selected from the study base as a stratified random sample accounting for age, sex, and residency. Men with a self reported history of work with rock drilling, stone crushing, or exposure to stone dust in general were defined as silica exposed. Rheumatoid factor (RF) status among cases was recorded.

Results: Silica exposed men had increased risk of rheumatoid arthritis, with an odds ratio (OR), adjusted for age, residential area, and smoking, of 2.2 (95\% confidence interval, 1.2 to 3.9) among men aged 18 to 70 years, and 2.7 (1.2 to 5.8) among those aged 50 to 70 years. Men who had worked with rock drilling or stone crushing (regarded as highly exposed) had a slightly greater increase in risk of rheumatoid arthritis than silica exposed men in general, with an OR of 3.0 (1.2 to 7.6). The joint effects of silica exposure and smoking were compatible with synergy between these two exposures in the development of rheumatoid arthritis but this was not conclusive.

Conclusions: Silica exposure is associated with increased risk of developing rheumatoid arthritis. This association is not explained by smoking habits.
$\mathrm{T}$ he pathogenesis of rheumatoid arthritis is likely to reflect genetic as well as environmental factors. Smoking has been found to increase the risk ${ }^{1-3}$ but little is known about the influence of other environmental factors. ${ }^{4}$

Six previous epidemiological studies have investigated the association between exposure to silica through the respiratory tract and the risk of rheumatoid arthritis. ${ }^{5-10}$ In these studies, an increased risk for the disease was observed among silica exposed persons from certain occupations or workplaces, ${ }^{5-79}$ and among persons with manifest silicosis. ${ }^{58}$ The number of observed cases was, however, small (between 9 and 43) in three of the studies, ${ }^{689}$ and only two studies defined cases according to established clinical criteria. ${ }^{5} 10$ Furthermore, only two of the studies (one of which had a total of 43 observed cases $^{6}$ ) adjusted the results for the potential confounding by smoking. ${ }^{6} 10$

To investigate further the association between silica exposure and the risk of developing rheumatoid arthritis, we analysed data from a population based case-control study, in which information about silica exposure as well as about smoking habits had been collected, and where cases were defined according to established clinical criteria.

\section{METHODS}

This study is a part of the EIRA ("epidemiological investigation of rheumatoid arthritis") study, which is an extensive population based case-control study, using incident cases of rheumatoid arthritis from the population aged 18 to 70 years of a geographically defined area of Sweden. The present report is based on analysis of the 276 male cases and 276 male controls included from May 1996 to June 2001. The 654

* The members of the group are listed at the end of the article female cases and the 791 female controls gathered during the same period were excluded from this study because of the small number of silica exposed women.

\section{Case definition and identification}

A case was defined as a person from the study base who was recently diagnosed with rheumatoid arthritis according to the American College of Rheumatology (ACR) 1987 criteria. ${ }^{11}$ All potential cases were diagnosed by rheumatologists. All hospital based rheumatology units, as well as most of the very few privately run rheumatology units in the study area, participated in the study. In all, 19 centres reported cases to the study, of which 15 were "early arthritis clinics". ${ }^{12}$

Rheumatoid factor (RF) status was determined by the units entering the cases into the study, and was reported to the study as RF positivity or RF negativity only.

\section{Selection of controls}

For each potential case a control was randomly selected from the study base as a stratified random sample accounting for age, sex, and residential area. The selection of the controls involved the use of the national population register, which is continuously updated. If information from one control was lacking, another was selected by the same principles.

\section{Data collection}

Information about environmental exposure was collected using an identical questionnaire in cases and controls. This was given to the cases shortly after they had received

Abbreviations: ACR, American College of Rheumatology; EIRA, epidemiological investigation of rheumatoid arthritis 
information about the diagnosis, and was sent by mail to the controls. Completed questionnaires were obtained from $96 \%$ of the case group and $77 \%$ of the controls.

Unanswered or incompletely answered questionnaires were completed by mail or by telephone by trained interviewers.

\section{Exposure}

The questionnaire contained a wide spectrum of questions regarding heredity, life style factors, health aspects, body height and weight, and socioeconomic and demographic factors, and detailed questions about occupations, occupational tasks, and exposures during different periods. The classification of exposure in this study was entirely based on the answers by the study subjects to the questions posed in this questionnaire.

For each case the time of the first symptoms of rheumatoid arthritis was used to estimate disease onset. The year in which symptoms first occurred was defined as the index year. The same index year was used for the corresponding control. Only data on exposures up to the index year were analysed.

We asked about occupational exposure using the following question: "Have you ever been in contact with any of the work tasks, handlings, and chemical compounds below, and if so, during which year/years? (If relevant, you may report more than one period)". This question was followed by a list of 42 specified items to be answered with a "no" or a "yes" for each of the listed items, with specification of the year in which the exposure started and ended and the number of hours per week of exposure. Answers regarding each exposure could be given for two different time periods but not more.

Study subjects reporting that they had ever worked with rock drilling or stone crushing or that they had ever been exposed to stone dust during the index year or before were classified as silica exposed.

Rock drilling and stone crushing are associated with substantial levels of silica exposure, ${ }^{13}{ }^{14}$ and are also work tasks that are rather easily recalled, whereas self reported exposure to stone dust in general may be more vague. We therefore considered rock drillers and stone crushers as belonging to a category with higher levels of silica exposure and with more accurate information about silica exposure than those exposed to silica in general.

\section{Potential confounding factors}

Age, residential area, socioeconomic class, and smoking habits were considered as potential confounding factors in the analyses of the association between silica exposure and rheumatoid arthritis.

Age was categorised into the following 10 strata: 18-24, 25-29, 30-34, 35-39, 40-44, 45-49, 50-54, 55-59, 60-64, and 65-70 years.

The last occupation during the year before the index year was used as a marker for socioeconomic class, which was categorised into the following five strata: 1, workers within the production of goods; 2, workers in the service sector; 3 , salaried employees at lower and intermediate levels; 4, salaried employees at higher levels, executives, university graduates; 5, others (pensioners, students, individuals working from home, and unemployed).

Physical workload was classified according to the frequency of lifting or carrying of heavy items (heavier than $10 \mathrm{~kg})$.

Subjects who reported that they were regularly smoking cigarettes during the index year or before were defined as ever smokers, and those who reported that they had never smoked tobacco before or during the index year were defined as never smokers.

\section{Statistical analyses}

Silica exposed subjects were compared with unexposed subjects with regard to the incidence of seropositive rheumatoid arthritis (RF+), seronegative rheumatoid arthritis $(\mathrm{RF}-)$, and rheumatoid arthritis overall by calculating the odds ratio with $95 \%$ confidence interval (CI) by conditional regression analysis. Odds ratios were adjusted for potential confounding from age, sex, residential area (design variables) and smoking (where appropriate). Adjustment for socioeconomic class and physical workload only marginally changed the estimates and was not retained in the final analyses. Odds ratios were interpreted as relative risks (RR), as the study was population based and the controls were a random sample from the study base. ${ }^{15}$ Separate analyses were made for subjects considered to be highly exposed to silica compared with those classified as unexposed to silica. Interaction between silica exposure and smoking habits was evaluated, using departure from additivity of effects as the criterion of interaction, as suggested by Rothman et al. ${ }^{16}$ The attributable proportion due to interaction (the proportion of the incidence of rheumatoid arthritis among the silica exposed ever smokers that was attributed to interaction between silica exposure and smoking) was calculated, with its $95 \%$ confidence interval. ${ }^{17}$ All analyses were done using the Statistical Analysis System (SAS), version 8.2. ${ }^{18}$

\section{RESULTS}

Of the 276 male cases in this study, 41 were silica exposed. About two thirds of the silica exposed cases were found to have experience in occupations associated with the building industry (construction workers, drivers, electricians, sanitary engineers, painters, stone masons, rock drillers, gardeners, brick layers, and floor layers). The mean duration of silica exposure among the exposed cases and the exposed controls was 20 and 17 years, respectively. Thirty seven (90\%) of the 41 silica exposed cases and 15 (75\%) of the 20 silica exposed controls had ever been cigarette smokers (table 1).

Silica exposed men had an increased risk of developing rheumatoid arthritis overall when compared with unexposed men, with an odds ratio of 2.2 (95\% CI, 1.2 to 3.9), adjusted for age, residential area, and smoking. When older subjects (50 to 70 years of age) were analysed separately, the odds ratio was 2.7 ( 1.2 to 5.8 ) (table 2 ).

The attributable proportion due to silica exposure was about 0.08 when all cases in the study were considered and about 0.55 for the silica exposed cases. When restricting the analyses to the group assumed to be highly exposed-that is, those who had worked with rock drilling or stone crushingthe odds ratio for rheumatoid arthritis overall was 3.0 (95\% CI, 1.2 to 7.6 ) (table 2). There was no significant difference between odds ratios for RF- and RF+ rheumatoid arthritis.

An increased risk of rheumatoid arthritis was only apparent among the silica exposed men who were ever smokers (table 3).

Table 1 Categories of silica exposure and smoking habits among silica exposed RA cases and silica exposed controls

\begin{tabular}{lll}
\hline $\begin{array}{l}\text { Category of silica } \\
\text { exposure }\end{array}$ & $\begin{array}{l}\text { Number of exposed } \\
\text { cases/controls* }\end{array}$ & $\begin{array}{l}\text { Number of smokers } \\
\text { among exposed cases/ } \\
\text { controls* }\end{array}$ \\
\hline Rock drilling & $12 / 6$ & $10 / 3$ \\
Stone crushing & $9 / 5$ & $9 / 4$ \\
Stone dust (unspecified) & $33 / 18$ & $30 / 14$ \\
Silica exposure overall & $41 / 20$ & $37 / 15$
\end{tabular}

*Cases and controls may belong to more than one category of silica exposure. 
Table 2 Odds ratios for rheumatoid arthritis (rheumatoid factor positive, rheumatoid factor negative, and overall) among subjects exposed to silica overall and among those who had worked with rock drilling or stone crushing, compared with unexposed subjects

\begin{tabular}{|c|c|c|c|c|c|c|c|}
\hline & \multirow[b]{2}{*}{ Age group (years) } & \multicolumn{3}{|c|}{ Subjects exposed to silica overall $v$ unexposed } & \multicolumn{3}{|c|}{$\begin{array}{l}\text { Subjects who had worked with rock drilling or stone } \\
\text { crushing } v \text { unexposed }\end{array}$} \\
\hline & & $\begin{array}{l}\text { No of exposed } \\
\text { cases }\end{array}$ & $\mathrm{OR}^{*}$ & $95 \% \mathrm{Cl}$ & $\begin{array}{l}\text { No of exposed } \\
\text { cases }\end{array}$ & $\mathrm{OR}^{*}$ & $95 \% \mathrm{Cl}$ \\
\hline \multirow{3}{*}{$R F+R A$} & 18 to 49 & 7 & 1.4 & 0.4 to 4.5 & 2 & 4.1 & 0.3 to 53.5 \\
\hline & 50 to 70 & 20 & 2.2 & 0.8 to 5.8 & 13 & 3.2 & 0.8 to 12.0 \\
\hline & 18 to 70 & 27 & 1.9 & 0.9 to 4.0 & 15 & 3.5 & 1.1 to 11.2 \\
\hline \multirow[t]{3}{*}{$R F-R A$} & 18 to 49 & 3 & 1.8 & 0.1 to 25.8 & 1 & 0.7 & 0.0 to 18.1 \\
\hline & 50 to 70 & 11 & 3.3 & 0.9 to 12.3 & 3 & 3.0 & 0.3 to 28.8 \\
\hline & 18 to 70 & 14 & 2.1 & 0.8 to 5.1 & 4 & 1.7 & 0.3 to 9.3 \\
\hline \multirow[t]{3}{*}{ Total RA } & 18 to 49 & 10 & 1.6 & 0.6 to 4.4 & 3 & 2.6 & 0.4 to 18.1 \\
\hline & 50 to 70 & 31 & 2.7 & 1.2 to 5.8 & 16 & 3.3 & 1.1 to 10.1 \\
\hline & 18 to 70 & 41 & 2.2 & 1.2 to 3.9 & 19 & 3.0 & 1.2 to 7.6 \\
\hline
\end{tabular}

${ }^{*}$ Adjusted for the potential confounding from age, residential area, and cigarette smoking.

$\mathrm{Cl}$, confidence interval; OR, odds ratio; RA, rheumatoid arthritis; RF, rheumatoid factor.

The attributable proportion due to interaction between silica exposure and smoking was estimated to be 0.6 (95\% CI, 0.1 to 1.1$)$.

\section{DISCUSSION}

Silica exposed men had a twofold increased risk of developing rheumatoid arthritis compared with unexposed men. When older men ( 50 to 70 years) and younger men ( 18 to 49 years) were analysed separately, a 2.5-fold increased risk was found among silica exposed men in the older age group, while no increase in risk was seen among the younger men. A somewhat stronger association was observed among persons who had been working with rock drilling or stone crushing, who had a threefold increased risk.

Our data on exposure were reported retrospectively by the cases and controls. This strategy runs the risk of misclassification of exposure because of recall bias, which needs to be considered carefully when interpreting the results. However, the risk of misclassification of exposure because of recall bias was limited in our study because significant dust exposure, particularly when related to an occupation or a work place, has a long duration and commonly occurs in circumstances that are easy to recall. There is still a risk that some silica exposed subjects were classified as unexposed, because silica exposure may occur in the absence if visible dust. Such exposure would probably be unrelated to disease and consequently biases these estimates of relative risks towards the null value.

All potential cases in the present study were examined carefully by a rheumatologist using a structured form to specify concordance with the ACR criteria, and only subjects who fulfilled these criteria were defined as cases. The risk of a substantial misdiagnosis of disease in this study is thus very limited.

Silica exposure may theoretically be linked to other environmental exposures as well as to lifestyle factors and socioeconomic circumstances that may in themselves be related to the possibility of developing rheumatoid arthritis. Adjustments were therefore made for potential differences in smoking habits, age, and residential area between individuals who were silica exposed and those who were not. Adjustment of all results for the potential confounding from socioeconomic class and physical workload were also made, but this affected the results only marginally and is not presented in our report.

If participation is related to silica exposure, this may introduce a selection bias in the estimated odds ratios. The risk of such bias in the present study was limited by the high participation rate $(96 \%$ among cases and $77 \%$ among controls). If the observed increased risk among silica exposed subjects was entirely the result of selection bias (that is, the true odds ratio was 1.0), it can be estimated that $30 \%$ of the non-responding controls would have been exposed to silica, which is highly unlikely.

All rheumatology units linked to the general welfare system, as well as privately run rheumatology units within the study area, reported cases to the study. Nevertheless, some cases might have been unidentified. There might, for instance, be cases diagnosed at other health care facilities that were never referred to a participating unit. We consider it unlikely that these unidentified cases would differ

Table 3 Odds ratios for rheumatoid arthritis (rheumatoid factor positive, rheumatoid factor negative, and overall) for different combinations of silica exposure and cigarette smoking compared with never smokers unexposed to silica

\begin{tabular}{|c|c|c|c|c|c|c|}
\hline & \multicolumn{3}{|c|}{ Absence of silica exposure } & \multicolumn{3}{|c|}{ Silica exposure } \\
\hline & No of cases & $\mathrm{OR}^{*}$ & $95 \% \mathrm{Cl}$ & No of cases & $\mathrm{OR}^{*}$ & $95 \% \mathrm{Cl}$ \\
\hline \multicolumn{7}{|l|}{$R F+R A$} \\
\hline Never smoked & 27 & 1.0 & - & 3 & 1.8 & 0.4 to 9.0 \\
\hline Ever smoked & 126 & 2.8 & 1.5 to 5.1 & 24 & 5.4 & 2.1 to 14.0 \\
\hline \multicolumn{7}{|l|}{$R F-R A$} \\
\hline Never smoked & 30 & 1.0 & - & 1 & 0.4 & 0.0 to 8.1 \\
\hline Ever smoked & 45 & 0.4 & 0.2 to 1.0 & 13 & 1.6 & 0.4 to 7.2 \\
\hline \multicolumn{7}{|l|}{ Total RA } \\
\hline Never smoked & 57 & 1.0 & - & 4 & 1.1 & 0.3 to 4.4 \\
\hline Ever smoked & 171 & 1.4 & 0.9 to 2.3 & 37 & 3.7 & 1.7 to 8.1 \\
\hline
\end{tabular}

*Adjusted for the potential confounding from age and residential area.

$\mathrm{Cl}$, confidence interval; $\mathrm{OR}$, odds ratio; RA, rheumatoid arthritis; $\mathrm{RF}$, rheumatoid factor. 
substantially with regard to exposure from those who were identified.

Persons with occupational silica exposure generally do physically demanding work. This may increase the likelihood that they will seek help from the health care system in comparison with those doing lighter work. This potential difference between silica exposed and non-exposed individuals in attendance at health care facilities could lead to a difference in the rate of identified cases in the two groups. Adjustment for physical workload did not, however, affect the estimates of the relative risk associated with silica exposure.

In summary, we believe that the present observation of an increased risk of developing rheumatoid arthritis among subjects exposed to silica is real and not an artefact. Previous observations of a possible association between silica exposure and development of rheumatoid arthritis have been reported from different parts of the world, such as north America, South Africa, Britain, and Scandinavia. ${ }^{5-10}$ As previously mentioned in the introduction, only two of these studies adjusted for the potential confounding from smoking. ${ }^{6} 10$

As smoking has been shown to be an environmental risk factor for rheumatoid arthritis, ${ }^{1-3}$ and considering that a correlation between silica exposure and smoking is probable in many contexts, it appears mandatory to take smoking into account when analysing the link between silica exposure and rheumatoid arthritis. In the present study silica exposure was found to be associated with an increased risk of developing rheumatoid arthritis even after adjustment for smoking. Our results were compatible with a synergistic effect of smoking and silica exposure, but did not allow a firm conclusion on this to be drawn owing to the small numbers of silica exposed subjects who had never smoked.

The mechanisms behind the biological effects of silica are still not fully understood. It has previously been proposed that increased release of inflammatory mediators from alveolar macrophages phagocytosing inhaled silica particles may activate macrophages/monocytes and lymphocytes systemically as well as in the rheumatoid synovium. ${ }^{19-25}$ These cell types also have the potential to increase the production of matrix metalloproteinases (MMP) - enzymes involved in the degradation and remodelling of extracellular matrix, which have been shown to be associated with rheumatoid arthritis as well as with silicosis. ${ }^{26-29}$

The production of MMP, as well as of inflammatory mediators such as tumour necrosis factor $\alpha$ and interleukin $1 \beta$, is regulated by the transcription factor nuclear factor $\kappa B$, the activity of which appears to be influenced by silica exposure. $^{30-34}$

\section{Conclusions}

Our results, which are based on data from the general population of a part of Sweden, show that silica exposure is a risk factor for the development of rheumatoid arthritis, even when smoking habits are taken into account. This will affect our understanding of the types of environmental stimuli that can trigger the onset of the disease process in rheumatoid arthritis.

\section{MEMBERS OF THE EIRA STUDY GROUP}

Ingeli Andreasson, Landvetter; Eva Baecklund (Akademiska Hospital); Ann Bengtsson, Thomas Skogh (Linköping University Hospital); Johan Bratt, Ingiäld Hafström (Huddinge University Hospital); Kjell Huddenius (Rheumatology Clinic in Stockholm City); Shirani Jayawardene (Bollnäs Hospital); Ann Knight, Hudiksvall Hospital; Ido Leden (Kristianstad Hospital); Thomas Lerndal, Göran Lindahl (Danderyds Hospital); Bengt Lindell (Kalmar Hospital); Christin Lindström, Gun Sandahl (Sophiahemmet); Björn Löfström (Katrineholm
Hospital); Birgitta Nordmark (Karolinska Hospital); Ingemar Petersson (Spenshult Hospital); Christoffer Schaufelberger (Sahlgrenska University Hospital); Patrik Stolt (Västerås Hospital); Berit Sverdrup (Eskilstuna Hospital); Olle Svernell (Västerviks Hospital); Tomas Weitoft (Gävle Hospital).

\section{ACKNOWLEDGEMENTS}

We want to thank Marie-Louise Serra for excellent assistance in collection of data. Thanks to Associate Professor R A Harris for linguistic advice. The study was supported by grants from the Swedish Medical Research Council, the Swedish Council for Working life and Social Research, the King Gustaf V's 80-year foundation, the Swedish Rheumatic Foundation, Stockholm County Council, and the insurance company AFA.

\section{Authors' affiliations}

P Stolt, H Källberg, B Sjögren, L Alfredsson, Institute of Environmental Medicine, Karolinska Institutet, Stockholm, Sweden

I Lundberg, National Institute of Working Life, Stockholm

L Klareskog, Rheumatology unit, Department of Medicine, Karolinska Hospital, Stockholm

L Alfredsson, Stockholm Centre for Public Health, Stockholm County

Council, Stockholm

\section{REFERENCES}

1 Stolt P, Bengtsson C, Nordmark B, Lindblad S, Lundberg I, Klareskog L, et al. Quantification of the influence of cigarette smoking on rheumatoid arthritis. Ann Rheum Dis 2003:62:835-41.

2 Vessey MP, Villard-Mackintosh L, Yeates D. Oral contraceptives, cigarette smoking and other factors in relation to arthritis. Contraception 1987; 35:457-64.

3 Heliövaara $M$, Aho K, Aromaa A, Knekt P, Reunanen A. Smoking and risk of rheumatoid arthritis. J Rheumatol 1993;20:1830-5.

4 Symmons D, Harrison B. Early inflammatory polyarthritis: results from the Norfolk Arthritis Register with a review of the literature. I. Risk factors for the development of inflammatory polyarthritis and rheumatoid arthritis. Rheumatology 2000;39:835-43.

5 Sluis-Cremer GK, Hessel PA, Hnizdo E, Churchill AR. Relationship between silicosis and rheumatoid arthritis. Thorax 1986;41:596-601.

6 Turner S, Cherry N. Rheumatoid arthritis in workers exposed to silica in the pottery industry. Occup Environ Med 2000;57:443-7.

7 Klockars M, Koskela RS, Jarvinen E, Kolari PJ, Rossi A. Silica exposure and rheumatoid arthritis: a follow up study of granite workers 1940-81. BMJ 1987; 18:997-1000

8 Rosenman KD, Moore-Fuller M, Reilly MJ. Connective tissue disease and silicosis. Am J Ind Med 1999:35:375-81.

9 Steenland K, Sanderson W, Calvert GM. Kidney disease and arthritis in a cohort study of workers exposed to silica. Epidemiology 2001;12:405-12.

10 Reckner-Olsson A, Skogh T, Axelsson O, Wingren G. Occupations and exposures in the work environment as determinants for rheumatoid arthritis. Occupational and environmental aspects on the aetiology of rheumatoid arthritis 2003. Linkoping University Medical Dissertations No 807.

11 Arnett FC, Edworthy SM, Bloch DA, McShane DJ, Fries JF, Cooper NS, et al. The American Rheumatism Association 1987 revised criteria for the classification of rheumatoid arthritis. Arthritis Rheum 1988;31:315-24.

12 Klareskog L, Nordmark B, Lindblad S. On the organization of an early arthritis clinic. Best Pract Res Clin Rheumatol 2001;15:1-15.

13 Bakke B, Stewart P, Eduard W. Determinants of dust exposure in tunnel construction work. Appl Occup Environ Hyg 2000;17:783-96.

14 Guenel P, Breum NO, Lynge E. Exposure to silica dust in the Danish stone industry. Scand J Work Environ Health 1989;15:147-53.

15 Miettinen OS. Estimatibility and estimation in case-referent studies. Am J Epidemiol 1976;103:226-35.

16 Rothman KJ, Greenland S, Walker AM. Concepts of interaction. Am J Epidemiol 1980;112:467-70.

17 Hosmer DW, Lemeshow S. Confidence interval estimation of interaction. Epidemiology 1992;3:452-6.

18 Cody RP, Smith JK. Applied statistics and the SAS programming language, 4th ed. New Jersey: Prentice Hall, 1997.

19 Parks CG, Conrad K, Cooper GC. Occupational exposure to crystalline silica and autoimmune disease. Environ Health Perspect 1999;107:793-802.

20 Zetterberg G, Elmberger G, Johansson A, Lundahl J, Lundborg M, Skold CM, et al. Rat alveolar and interstitial macrophages in the fibrosing stage following quartz exposure. Hum Exp Toxicol 2000;19:402-11.

21 Kinne RW, Brauer R, Stuhlmuller B, Palombo-Kinne E, Burmester GR. Macrophages in rheumatoid arthritis. Arthritis Res 2000;2:189-202.

22 Tomokuni A, Otsuki T, Isozaki Y, Kita S, Ueki H, Kusaka M, et al. Serum levels of soluble Fas ligand in patient with silicosis. Clin Exp Immunol 1999;1 18:441-4.

23 Ponchel F, Morgan AW, Bingham SJ, Quinn M, Buch M, Verburg RJ, et al. Dysregulated lymphocyte proliferation and differentiation in patients with rheumatoid arthritis. Blood 2002;100:4550-6. 
24 Leandro MJ, Edwards JC, Cambridge G. Clinical outcome in 22 patients with rheumatoid arthritis treated with B lymphocyte depletion. Ann Rheum Dis 2002;61:863-6.

25 Wahle M, Pierer M, Krause A, Kolker S, Baerwald CG. Decreased catecholamine-induced cell death in B lymphocytes from patients with rheumatoid arthritis. Ann NY Acad Sci 2002;966:425-8.

26 Goldbach-Mansky R, Lee JM, Hoxworth JM, Smith D, Duray $P$, Schumacher RH, et al. Active synovial matrix metalloproteinase-2 is associated with radiographic erosions in patients with early synovitis. Arthritis Res 2000;2: 145-53.

27 Green MJ, Gough AK, Devlin J, Smith J, Astin P, Taylor D, et al. Serum MMP 3 and MMP-1 and progression of joint damage in early rheumatoid arthritis. Rheumatology 2003;42:83-8.

28 Perez-Ramos J, de Lourdes Segura-Valdez M, Vanda B, Selman M, Pardo A Matrix metalloproteinases 2, 9, and 13 and tissue inhibitors of metalloproteinases 1 and 2 in experimental lung silicosis. Am J Respir Crit Care Med 1999; 160:1274-82.

29 Morimoto Y, Tsuda T, Nakamura H, Hori H, Yamato H, Nagata N, et al. Expression of matrix metalloproteinases, tissue inhibitors of metalloproteinases, and extracellular matrix mRNA following exposure to mineral fibers and cigarette smoke in vivo. Environ Health Perspect 1997:105:1247-51

30 Chen F, Sun SC, Kuh DC, Gaydos L, Demers LM. Essential role of NF-kappa B activation in silica-induced inflammatory mediator production in macrophages. Biochem Biophys Res Commun 1995;214:985-92.

31 Pacifico F, Barone C, Mellone S, Di Jeso B, Consiglio E, Formisano S, et al. Promoter identification of CIKS, a novel NF-kappaB activating gene, and regulation of its expression. Gene 2003;307:99-109.

32 Takaesu G, Surabhi RM, Park KJ, Ninomiya-Tsuji J, Matsumoto K, Gaynor RB. TAK 1 is critical for lkappaB kinase-mediated activation of the NF-kappaB pathway. J Mol Biol 2003;326:105-15.

33 Higuchi M, Manna SK, Sasaki R, Aggarwal BB. Regulation of the activation of nuclear factor kappaB by mitochondrial respiratory function: evidence for the reactive oxygen species-dependent and-independent pathways. Antioxid Redox Signal 2002;4:945-55.

34 Wang $\mathrm{T}$, Zhang $\mathrm{X}$, Li JJ. The role of NF-kappaB in the regulation of cell stress responses. Int Immunopharmacol 2002;2:1509-20. 